\title{
ESTUDO SOBRE A RESPONSABILIDADE SOCIAL CORPORATIVA E AS RECLAMAÇÕES PERTINENTES ÀS OUVIDORIAS DOS BANCOS, CONSIDERANDO O PORTE E O TIPO DE CONTROLE NO BRASIL
}

\author{
STUDY ON CORPORATE SOCIAL RESPONSIBILITY AND \\ OMBUDSMAN'S OFFICES COMPLAINTS OF BANKS, CONSIDERING \\ THE SIZE AND TYPE OF CONTROL IN BRAZIL
}

Data de submissão: 22/12/2013 Aceite: $13 / 07 / 2015$

Carlos André de Melo Alves ${ }^{1}$ Claudio Antonio Pinheiro Machado Filho ${ }^{2}$ Gerlando Augusto Sampaio Franco de Lima $^{3}$

\section{RESUMO}

No Brasil, as ouvidorias em bancos possuem a atribuição de atender clientes e usuários em última instância. Este artigo busca demonstrar a evolução dos assuntos das reclamações pertinentes às ouvidorias dos bancos, considerando o porte e o tipo de controle no Brasil. Realizou-se pesquisa exploratória numa amostra não probabilística de 26 bancos, entre públicos, privados nacionais e estrangeiros. Coletaram-se dados de 1.377 reclamações pertinentes às ouvidorias desses bancos, encerradas no 1 을 semestre de 2008 até o 1ㅇs semestre de 2011 e divulgadas pelo Banco Central do Brasil. No tratamento dos dados empregou-se estatística descritiva, estatística inferencial e Análise de Correspondência Múltipla. Constatou-se que o assunto 'Ouvidoria' predominou nas ocorrências de reclamações até o 10 semestre de 2009, enquanto outros assuntos prevaleceram a partir do 2 o semestre de 2009. Os assuntos 'Descumprimento de Prazo' e 'Outros e Discagem Direta Gratuita' foram mais condicionados aos bancos médios e privados nacionais. $\mathrm{O}$ assunto 'Atendimento' foi mais associado aos bancos muito grandes e públicos. Os resultados podem contribuir para aperfeiçoar as atribuições regulamentares das ouvidorias dos bancos e, também, podem contribuir para entender a implementação das ações socialmente responsáveis de bancos, para atender seus stakeholders, clientes e usuários no Brasil.

Palavras-chave: Responsabilidade Social Corporativa; Bancos; Reclamações; Ouvidorias; Porte; Tipo de Controle.

\footnotetext{
1 Possui graduação em Tecnologia em Processamento de Dados pela Unesp, Especialização em Gestão de Tecnologia da Informação pela Associação de Ensino Unificado do Distrito Federal, mestrado em Administração pela Universidade Federal do Paraná, doutorado em Administração pela Universidade de São Paulo. Brasília. Distrito Federal. Professor Adjunto do Departamento de Administração da Universidade de Brasília - UnB e Analista do Banco Central do Brasil. Brasil. E-mail: camelodfprof@gmail.com

2 pela Faculdade de Economia Administração e Contabilidade (FEA/USP). São Paulo. São Paulo. Brasil. E-mail: capfilho@usp.br

3 Possui graduação em Ciências Contábeis pela Universidade Federal do Rio Grande do Norte, mestrado e doutorado em Controladoria e Contabilidade pela Universidade de São Paulo. São Paulo. São Paulo. Brasil. E-mail: gerlando@usp.br
} 


\section{ABSTRACT}

In Brazil, the ombudsman's offices in banks has the function to deal with customers and users ultimately. This article seeks to demonstrate the evolution of the issues related to the ombudsman's offices complaints of banks, considering the size and type of control in Brazil. An exploratory research was carried out with a non-probabilistic sample of 26 public, domestic private and foreign banks. The data was collected from 1.377 complaints related to the ombudsman's offices of these banks, ended from the 1st semester of 2008 to the 1st semester of 2011 and released by the Central Bank of Brazil. Data analysis employed descriptive statistics, inferential statistics and Multiple Correspondence Analysis. It was ascertained that the complaint issue 'Ombudsman' predominated in the complaints occurrences until the 1st semester of 2009 while other complaint issues prevailed from the 2nd semester of 2009. The issues 'Term Breach' and 'Others and Dial Direct Free' were conditioned mostly to middle-size banks and domestic private ones, and 'Customer Service' was associated mostly to very large banks that are public. Results can contribute to enhance the banks' ombudsman's offices regulatory duties, and also can contribute to understand the implementation of socially responsible actions of banks to meet both customers and users as banks' stakeholders in Brazil.

Keywords: Corporate Social Responsibility; Banks; Complaints; Ombudsman's Offices; Size; Type of Control.

\section{INTRODUÇÃO 1}

De acordo com a Organisation for Economic Co-operation and Development - OECD, os princípios atualmente recomendados para a proteção do consumidor de produtos financeiros contemplam a manutenção de mecanismos para solucionar conflitos (OECD, 2011). Entre esses mecanismos, estão as ouvidorias, as quais podem atuar em diversos setores financeiros, dentre eles o setor bancário (BCBS, 2008). A partir de julho de 2007, no Brasil, essas ouvidorias tornaram-se obrigatórias, independente do porte ou do tipo de controle do banco.

As ouvidorias são a última instância em bancos para implementar o atendimento dos seus stakeholders. Neste estudo, stakeholders são partes interessadas (FREEMAN, 1994) contemplando clientes, usuários, acionistas, empregados, fornecedores e a comunidade. Devido ao papel dos bancos em economias nacionais, locais e sistemas financeiros, reguladores bancários e governos são, também, stakeholders (BCBS, 1999). Quanto aos clientes e usuários, a regulamentação mostra a ouvidoria tratando reclamações sem distinguir clientes (que possuam, por exemplo, uma conta corrente aberta no banco) daqueles que, sendo usuários, não são, necessariamente, clientes (por exemplo, usuários dos serviços de pagamento de contas de água, luz ou telefone) (ALVES; MACHADO FILHO, 2014). Baseado nessa regulamentação, neste estudo os usuários não são, necessariamente, clientes dos bancos.

Os clientes e usuários podem, ainda, buscar orientação de terceiros para resolver conflitos, por exemplo, do Banco Central do Brasil - BCB. A autarquia permite registro de reclamações contra bancos, mesmo quando o assunto reclamado diz respeito ao indício de descumprimento de normas pertinentes às ouvidorias. $\mathrm{O}$ número de reclamações registradas no $\mathrm{BCB}$ pode ser entendido como uma prova das ações socialmente responsáveis dos bancos, associada à melhoria do atendimento (CRUVINEL, 2008), sem prejuízo da análise dos assuntos reclamados, os quais estão sujeitos à investigação empírica e podem trazer evidências adicionais a respeito desse atendimento.

O objetivo desse artigo é demonstrar a evolução dos assuntos das reclamações pertinentes às ouvidorias dos bancos, considerando o porte e o tipo de controle no Brasil. Justifica-se esta pesquisa pelo tema deste estudo ser atual e pouco explorado, podendo os resultados deste trabalho subsidiar reflexões de acadêmicos e demais interessados na conduta dos bancos quanto ao cumprimento das atribuições regulamentares das ouvidorias. Considerando a perspectiva da 1 As opiniões neste estudo são dos autores e não refletem a opinião das entidades em que os autores trabalhem. 
responsabilidade social corporativa em bancos (HINSON; BOATENG; MADICHIE, 2010; YEUNG, 2011), o estudo pode contribuir para que a sociedade entenda melhor a implementação das ações socialmente responsáveis dos bancos para atender seus stakeholders no Brasil.

Complementando as justificativas, esta pesquisa pode, também, subsidiar a avaliação de políticas pertinentes à implementação das atribuições das ouvidorias, considerando, nessa avaliação, duas variáveis: porte e tipo de controle, ambas citadas no primeiro parágrafo desta introdução, as quais são baseadas em práticas recomendadas de governança corporativa (IBGC, 2009). Por fim, sob o aspecto metodológico, o estudo mostra aplicação original da técnica multivariada Análise de Correspondência Múltipla - ACM (FÁVERO et. al, 2009), usada para auxiliar a interpretação de dados qualitativos a respeito das ocorrências de reclamações no setor bancário brasileiro.

\section{REVISÃO DE LITERATURA}

Este capítulo abrange a responsabilidade social corporativa, enfatizando: os stakeholders em bancos (Seção 2.1), as reclamações de tais stakeholders contra bancos (Seção 2.2), as reclamações apresentadas ao BCB e que são pertinentes às ouvidorias (Seção 2.3) e as variáveis porte e tipo de controle (Seção 2.4).

\subsection{Responsabilidade Social Corporativa dos Bancos e seus Stakeholders}

De acordo com Oro, Renner e Braun (2013, p. 249) "o conceito de responsabilidade social corporativa vem sendo abordado ao longo do tempo, amplamente discutido e incorporado constantemente às empresas". A responsabilidade social corporativa associa-se ao desempenho dos negócios e pode ser entendida por meio de quatro dimensões não excludentes: responsabilidade econômica, responsabilidade legal, responsabilidade ética e responsabilidade discricionária (CARROLL, 1979).

A responsabilidade econômica abrange as obrigações de as empresas serem produtivas e rentáveis. A responsabilidade legal refere-se às expectativas da sociedade de que as empresas cumpram suas obrigações de acordo com o arcabouço legal existente. A responsabilidade ética refere-se às empresas que, dentro do contexto em que se inserem, tenham um comportamento apropriado de acordo com as expectativas existentes entre os agentes da sociedade. A responsabilidade discricionária pode ser considerada como uma extensão da dimensão ética (AKANBI; OFOEGBU, 2012; MACHADO FILHO, 2006).

Com relação à dimensão ética da responsabilidade social corporativa, a literatura apresenta correntes de pensamento que podem privilegiar diferentes visões, como a dos shareholders e a dos stakeholders (MACHADO FILHO; ZYLBERSTAJN, 2004). A visão dos shareholders enfatiza que a corporação tem por objetivo o aumento da riqueza do acionista. Considerando a visão dos stakeholders, busca-se o equilíbrio de interesses entre as partes interessadas no resultado da organização. Em outras palavras, busca-se atender aos interesses não só de acionistas, mas também de outros stakeholders (FREEMAN, 1994).

A identificação dos stakeholders, ao longo da trajetória histórica das empresas, constitui-se um desafio (TEIXEIRA; MORAES, 2013). Visto que bancos necessitam de recursos externos para alcançar seus objetivos, o atendimento aos seus stakeholders é uma questão estratégica. Por exemplo, os depósitos dos clientes constituem fontes de recursos para os bancos, capazes de superar os recursos próprios dessas entidades, o que enfatiza a importância do stakeholder cliente. Adicionalmente, a prestação de serviços é estendida aos usuários que não são clientes, mas podem ser tratados de forma similar aos clientes, conforme a regulamentação bancária (CMN, 2010). 
O atendimento dos stakeholders clientes e usuários em bancos é objeto de atenção, tanto no exterior quanto no Brasil. Na Inglaterra, por exemplo, o regulador recomenda aos bancos o tratamento justo a clientes e a usuários de serviços (MULLINEUX, 2011). No Brasil, o Edital de audiência pública 41/2012, de 13 de junho de 2012, informa que a implementação de uma política de responsabilidade socioambiental implica o atendimento às diretrizes e aos objetivos relacionados a diversos aspectos, dentre eles o relacionamento com clientes e usuários (BCB, 2012a). Um dos temas que diz respeito aos stakeholders clientes são as reclamações (CLARKSON, 1995).

\subsection{Reclamações Contra Bancos e os Stakeholders}

O estudo das reclamações de clientes e como as organizações lidam com elas tem despertado interesse de países em diversos continentes (RYNGELBLUM; VIANNA; RIMOLI, 2013). O campo de estudo das reclamações "[...] pode fornecer dados para o desenvolvimento de indicadores sociais" (DANET, 1978, p. 342). As reclamações podem, também, alertar as organizações quanto ao declínio da qualidade de produtos e serviços (HIRSCHMAN, 1970).

Algumas pesquisas internacionais vinculam o estudo das reclamações à responsabilidade social corporativa de bancos. O estudo de Hinson, Boateng e Madichie (2010) referiu-se à divulgação a respeito da responsabilidade social corporativa em bancos de Gana, e a presença/ ausência de reclamações permitiu avaliação de aspectos ligados a clientes. Segundo pesquisa de Yeung (2011), baseada em opiniões de acadêmicos e profissionais de finanças em Hong Kong, Estados Unidos e Escócia, os mecanismos para tratar as reclamações de clientes estão entre os elementos-chave da responsabilidade social corporativa de bancos.

No setor bancário brasileiro, as reclamações podem ser apresentadas aos canais de atendimento dos bancos. Se o atendimento não for satisfatório, as reclamações podem ser, também, apresentadas a terceiros. Para os fins desta pesquisa, terceiros são partes externas, não envolvidas numa relação (SINGH, 1988, 1990; CRIÉ, 2003). São exemplos de terceiros os Procons e o BCB. O registro das reclamações pelos Procons evidencia a busca de solução individual do problema, numa perspectiva consumerista, enquanto o registro de reclamações no $B C B$ não tem o fim de resolver o problema individual, mas de servir como insumo para ações buscando a conformidade dos bancos à regulamentação bancária (BCB, 2005; MINISTÉRIO DA JUSTIÇA, 2012).

A melhoria de atendimento bancário encontra-se entre as ações socialmente responsáveis relacionadas aos clientes, e uma prova associada a esse aspecto é o número de reclamações no BCB (CRUVINEL, 2008). Respaldado pela Circular $n^{\circ} 3.289$, de 31 de agosto de 2005, o BCB investiga se as reclamações por ele recebidas evidenciam descumprimento ou não de regulamentações do Conselho Monetário Nacional - CMN e do próprio BCB e, caso descumpram, são consideradas reclamações procedentes (ou denúncias).

As reclamações apresentadas ao BCB subsidiam a elaboração de rankings divulgados mensalmente, com a quantidade de reclamações e os assuntos das reclamações procedentes encerradas no mês (BCB, 2005, 2011c, 2012b). A presença dos bancos nesses rankings pode afetar a imagem deles perante clientes, usuários e outros stakeholders, possibilitando eventuais perdas reputacionais (FOMBRUN; GARDBERG; BARNETT; 2000).

\subsection{Reclamações Pertinentes às Ouvidorias de Bancos no Brasil}

Entre as reclamações apresentadas ao BCB, citadas na Seção 2.2, estão aquelas cujos assuntos dizem respeito ao indício de descumprimento de normas pertinentes às ouvidorias de ban- 
cos. As ouvidorias são a última instância para implementar o atendimento dos stakeholders clientes e usuários em bancos no Brasil. As ouvidorias foram inicialmente normatizadas pela Resolução no 3.477, de 26 de julho de 2007 (CMN, 2007a). A Resolução no 3.489 introduziu alterações complementares à Resolução no 3.477 (CMN, 2007b). Por sua vez, em 25 de março de 2010, a Resolução no 3.849 revogou as duas resoluções anteriormente citadas neste parágrafo (CMN, 2010).

Segundo a Resolução $n^{\circ} 3.849$, a ouvidoria é um componente organizacional que tem a atribuição de atuar como canal de comunicação entre bancos, clientes e usuários, inclusive na mediação de conflitos. A partir da vigência da Resolução ${ }^{\circ} 3.849$, o prazo de resposta das ouvidorias passou para 15 dias (o prazo anterior, dado pela Resolução n 3.477 , revogada no primeiro semestre de 2010, era 30 dias). Semestralmente, a ouvidoria deve elaborar um relatório acerca de suas atividades, o qual fica à disposição do BCB (CMN, 2007a, 2010).

$O$ Quadro 1 refere-se às reclamações pertinentes às ouvidorias, as quais podem ser apresentadas por clientes e usuários ao BCB. Os assuntos reclamados contemplam como irregularidades: o atendimento prestado pela ouvidoria, o descumprimento do prazo de resposta regulamentar, a não divulgação de telefone para acesso gratuito, via Discagem Direta Gratuita DDG, ou a sua não disponibilização e outros assuntos. Verifique-se, no Quadro 1, que os assuntos das reclamações pertinentes às ouvidorias iniciaram a vigência a partir do 1ㅇ semestre de 2008.

Quadro 1 - Irregularidades: reclamações pertinentes às ouvidorias de bancos no Brasil

\begin{tabular}{|c|c|}
\hline Irregularidade ${ }^{a}$ (Vigência ${ }^{b}$ ) & Aplicação \\
\hline \multirow{4}{*}{$\begin{array}{l}\text { Ouvidoria - Atendimento } \\
\text { (desde 01.05.2010) }\end{array}$} & $\begin{array}{l}\text { Art. 1o, parágrafo } 20 \text {, inciso II, da Resolução } 3.849 / 10 \text {, combinado com o } \\
\text { art. } 20 \text {, inciso I, da mesma Resolução (o demandante informa que não con- } \\
\text { segue ser atendido pela Ouvidoria ou quando esse componente o remete } \\
\text { para outros canais de atendimento já procurados pelo demandante); }\end{array}$ \\
\hline & $\begin{array}{l}\text { Art. 20, parágrafo } 10 \text {, da Resolução } 3.849 / 10 \text { (não fornecimento do } \\
\text { protocolo de atendimento); }\end{array}$ \\
\hline & $\begin{array}{l}\text { Art. } 2 \text { - incisos II e III, da Resolução } 3.849 / 10 \text { (a Ouvidoria registra a } \\
\text { reclamação, mas, em seguida se nega a prestar esclarecimentos ou } \\
\text { informar o prazo para resposta); }\end{array}$ \\
\hline & Para outros problemas relacionados a atendimento de Ouvidoria. \\
\hline $\begin{array}{l}\text { Ouvidoria - Descumprimento do } \\
\text { Prazo de Resposta } \\
\text { (desde 27.08.2009) }\end{array}$ & $\begin{array}{l}\text { Art. 20, incisos III e IV, da Resolução } 3849 / 10 \text {. } \\
\text { Nota: A Ouvidoria deve fixar prazo de resposta, que não pode ser } \\
\text { superior a } 15 \text { dias }^{\text {c. }}\end{array}$ \\
\hline $\begin{array}{l}\text { Ouvidoria - Não Disponibilização } \\
\text { de DDG d (desde 27.08.2009) }\end{array}$ & Art. 1으, parágrafo 2ㅇ, inciso III, da Resolução 3849/10. \\
\hline $\begin{array}{l}\text { Ouvidoria - Não Divulgação do } \\
\text { DDG }{ }^{\text {}} \text { (desde 27.08.2009) }\end{array}$ & Art. 1ํ, parágrafo 2º, inciso III, alíneas "a", "b" e "c", da Resolução 3849/10. \\
\hline $\begin{array}{l}\text { Ouvidoria - Outros } \\
\text { (desde 27.08.2009) }\end{array}$ & Para problemas não especificados nos demais itens desse assunto (IF). \\
\hline $\begin{array}{c}\text { Ouvidoria } \\
(08.02 .2008-27.08 .2009)\end{array}$ & Resolução 3.477/07 - Instituições Financeiras. \\
\hline
\end{tabular}

Fonte: dados da pesquisa. Observações: ${ }^{\text {a. }}$ referente às instituições financeiras; ${ }^{\text {b. }}$ referente à vigência para abertura da

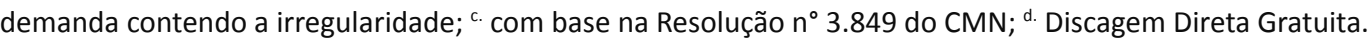

Enquanto as reclamações a respeito do atendimento da ouvidoria permitem reflexões aplicáveis à interação entre a equipe da ouvidoria e os clientes/usuários da instituição bancária, as reclamações a respeito do descumprimento de prazo de resposta permitem reflexões aplicáveis ao processamento das demandas pelas ouvidorias. Nesse processamento, a ouvidoria pode solicitar informações a outras áreas do banco para completar uma investigação (DANET, 1978). O tempo de retorno dessas áreas a tal solicitação pode influenciar o prazo de resposta conclusiva aos stakeholders clientes ou usuários. 


\subsection{Porte e Tipo de Controle}

O porte e o tipo de controle são variáveis lembradas em práticas recomendadas de governança corporativa, divulgadas pelo Instituto Brasileiro de Governança Corporativa - IBGC (2009). Neste estudo, são chamadas, também, variáveis de governança corporativa.

Em pesquisas a respeito do mercado financeiro, há várias formas para operacionalizar o porte. Pode-se, por exemplo, empregar dados contábeis, como o valor dos ativos (DICK, 2008) ou o valor do patrimônio líquido (MILANI; CERETTA, 2013). Pode-se, também, operacionalizar o porte usando dados cadastrais, como o número de empregados (LLIEHAUSEN; WOLKEN, 1990) ou o número de clientes garantidos pelo Fundo Garantidor de Créditos - FGC (BCB, 2011a, 2011c). Baseado em dados quantitativos, pode-se segmentar o porte em quartis qualificados em 'pequeno', 'médio', 'grande' ou 'muito grande' (LIMA, 2007). Neste estudo, o porte baseia-se no número de clientes garantidos pelo FGC.

Há, também, diversas formas para segmentar o tipo de controle. O IBGC, por exemplo, contempla categorias, entre elas o setor público e o estrangeiro (IBGC, 2009). No setor bancário, o tipo de controle pode ser obtido com base em informações disponibilizadas pelo BCB e segmentado em três atributos: 'controle público', 'controle privado nacional' e 'controle estrangeiro' (BCB, 2011d; BERGER, et al., 2005; CRUVINEL, 2008). A classificação do tipo de controle adotada nesta pesquisa emprega três atributos.

Segundo a introdução, a regulamentação informa que as ouvidorias são obrigatórias, independente do porte ou do tipo de controle do banco (CMN, 2010). Apesar dessa previsão regulamentar, pode-se verificar se bancos com diferentes portes ou diferentes tipos de controle condicionam-se aos mesmos assuntos reclamados num determinado período. Tal verificação pode subsidiar a avaliação de políticas pertinentes à implementação das atribuições das ouvidorias, considerando, nessa avaliação, os atributos das variáveis de governança corporativa.

\section{MÉTODO}

Além da revisão de literatura, este trabalho aborda uma pesquisa empírica exploratória (SAMPIERI; COLLADO; LUCIO, 2006). A população contempla bancos constantes do relatório ' 50 Maiores Bancos e o Consolidado do Sistema Financeiro Nacional' - Consolidado Bancário I (Consolidado B-I), totalizando 100 entidades na data base junho de 2011 (BCB, 2011d). O Consolidado B-I foi escolhido por abranger bancos representativos em ativos totais para o Sistema Financeiro Nacional - SFN. Na referida data base, esse consolidado representou $83,90 \%$ dos ativos totais de todo o SFN. A amostra é não probabilística por acessibilidade aos dados (Quadro 2).

Para se chegar aos bancos da amostra a partir da população, inicialmente foram consultados cadastros de instituições financeiras divulgados pelo BCB, selecionando-se 90 bancos ativos e operacionalmente independentes de outros bancos do início do 10 semestre de 2008 ao fim do 1 o semestre de 2011. Justifica-se o interesse em investigar esse período por abranger as primeiras reclamações recebidas pelo BCB cujos assuntos foram pertinentes às ouvidorias. Os referidos assuntos baseiam-se no Quadro 1 da revisão de literatura.

A partir desses 90 bancos, foram selecionados 30 deles que apresentaram reclamação pertinente à ouvidoria e estiveram presentes nos rankings de reclamações divulgados no mesmo período. Entre os 30 bancos listados, foram selecionados 26 bancos, com informações financeiras comparáveis no período analisado, ouvidor e sitio eletrônico evidenciado (BCB, 2011b). A comparabilidade baseou-se nas informações dos próprios bancos da amostra, citados no Quadro 2. 
Os depósitos totais dos bancos da amostra representaram 79,44\% do Consolidado B-I e $60,35 \%$ do total de clientes garantidos pelo FGC, na data base junho de 2011. Esses percentuais indicam a representatividade da amostra em depósitos totais para o Consolidado B-I e em número de clientes para o SFN. O Quadro 2 mostra, também, colunas com atributos das variáveis Porte e Tipo de Controle. Essas variáveis foram citadas na Seção 2.4 da revisão de literatura e baseiam-se em práticas recomendadas de governança corporativa (IBGC, 2009). Durante os sete (7) semestres a que se refere este estudo, cada banco manteve o Porte e o Tipo de Controle descritos no Quadro 2. Para atingir os objetivos do estudo, não foi preciso identificar os bancos nas análises dos resultados.

Quadro 2-Amostra ${ }^{a, b}$

\begin{tabular}{|c|c|c|c|c|c|}
\hline Nome reduzido & Porte & Tipo de controle & Nome reduzido & Porte & Tipo de controle \\
\hline BANESE & Grande & Público & FIBRA & Médio & Privado Nacional \\
\hline BANRISUL & $\begin{array}{l}\text { Muito } \\
\text { Grande }\end{array}$ & Público & HSBC & $\begin{array}{c}\begin{array}{c}\text { Muito Gran- } \\
\text { de }\end{array} \\
\end{array}$ & Estrangeiro \\
\hline BASA & Grande & Público & $\begin{array}{l}\text { INDUSTRIAL DO } \\
\text { BRASIL }\end{array}$ & Pequeno & Privado Nacional \\
\hline BASEMSA & Pequeno & Privado Nacional & ITAÚ & $\begin{array}{c}\begin{array}{c}\text { Muito Gran- } \\
\text { de }\end{array} \\
\end{array}$ & Privado Nacional \\
\hline BB & $\begin{array}{l}\text { Muito } \\
\text { Grande }\end{array}$ & Público & J. MALUCELLI & Pequeno & Privado Nacional \\
\hline $\mathrm{BIC}$ & Grande & Privado Nacional & MATONE & Pequeno & Privado Nacional \\
\hline BMG & Médio & Privado Nacional & $\begin{array}{l}\text { MERCANTIL DO } \\
\text { BRASIL }\end{array}$ & Grande & Privado Nacional \\
\hline BONSUCESSO & Médio & Privado Nacional & PINE & Pequeno & Privado Nacional \\
\hline BVA & Médio & Privado Nacional & RURAL & Grande & Privado Nacional \\
\hline CEF & $\begin{array}{l}\text { Muito } \\
\text { Grande }\end{array}$ & Público & SAFRA & Grande & Privado Nacional \\
\hline CITIBANK & Grande & Estrangeiro & SANTANDER & $\begin{array}{c}\text { Muito Gran- } \\
\text { de }\end{array}$ & Estrangeiro \\
\hline CRUZEIRO DO SUL & Médio & Privado Nacional & SOCIÉTÉ GÉNÉRALE & Pequeno & Estrangeiro \\
\hline DAYCOVAL & Médio & Privado Nacional & VOTORANTIM & Médio & Privado Nacional \\
\hline
\end{tabular}

Fonte: dados da pesquisa. Observações: ${ }^{\text {a. }}$ bancos ordenados alfabeticamente por nome reduzido, na data base junho de 2011; b. durante os sete semestres a que se refere a pesquisa, cada banco manteve o Porte e o Tipo de Controle descritos nesse quadro.

A coleta dos dados contemplou as reclamações pertinentes às ouvidorias dos bancos da amostra. Essas reclamações foram encerradas do 1ㅇs semestre de 2008 ao 1 ㅇ semestre de $2011 \mathrm{e}$ disponibilizadas publicamente nos relatórios intitulados Ranking de Reclamações (BCB, 2011c). $O$ levantamento de 42 rankings mensais, nos 7 semestres a que se referem esta pesquisa, permitiu apurar 1.377 reclamações procedentes. A consolidação das reclamações por semestre considerou a periodicidade de elaboração do relatório acerca da atuação da ouvidoria, citado na Seção 2.3 da revisão de literatura (CMN, 2010).

Um detalhamento do significado dos assuntos reclamados pertinentes às ouvidorias (Quadro 1) foi obtido em resposta a um pedido de informação ao BCB, por meio do preenchimento do formulário 'Fale Conosco', disponível ao público e acessado em maio de 2011. Além do assunto reclamado, a descrição das demais variáveis empregadas na parte empírica da pesquisa (porte, tipo de controle e semestre), as formas de operacionalização dessas variáveis e suas respectivas fontes de evidência estão no Quadro 3. 
Quadro 3 - Operacionalização das Variáveis

\begin{tabular}{|c|c|c|c|}
\hline Variável & Atributos da Variável & Fonte de Evidência & Principais Referências \\
\hline Assunto & $\begin{array}{c}\text { 'Ouvidoria'; } \\
\text { ‘Ouvidoria - Atendimento', } \\
\text { ‘Ouvidoria - Descumprimento } \\
\text { de Prazo de Resposta'; } \\
\text { ‘Ouvidoria - Outros e DDG' a. }\end{array}$ & $\begin{array}{l}\text { Coluna 'Assunto' dos dados do re- } \\
\text { latório Ranking de Reclamações, } \\
\text { complementado com Quadro } 1 .\end{array}$ & BCB $(2005,2011 c)$. \\
\hline Semestre & $\begin{array}{l}\text { '200801'; '200802'; '200901'; } \\
\text { '200902'; '201001'; '201002'; } \\
\text { '201101'. }\end{array}$ & $\begin{array}{l}\text { Quatro últimos dígitos do item 'Pe- } \\
\text { ríodo', junto com o semestre de di- } \\
\text { vulgação da reclamação proceden- } \\
\text { te, constantes do relatório Ranking } \\
\text { de Reclamações }\end{array}$ & $\begin{array}{l}\text { BCB (2011c); } \\
\text { Greenacre (2002); } \\
\quad \text { Lima (2007). }\end{array}$ \\
\hline Porte & $\begin{array}{l}\text { 'Muito Grande'; } \\
\text { 'Grande'; } \\
\text { 'Médio'; } \\
\text { 'Pequeno'. }\end{array}$ & $\begin{array}{l}\text { Segmentação em quartis }{ }^{d} \text { do nú- } \\
\text { mero de clientes garantidos pelo } \\
\text { FGC, posição mais atualizada ao } \\
\text { fim de cada semestre no relatório } \\
\text { 'Ranking de Reclamações'. }\end{array}$ & $\begin{array}{l}\text { BCB (2011c); } \\
\text { IBGC (2009); } \\
\text { Lima (2007). }\end{array}$ \\
\hline $\begin{array}{l}\text { Tipo de } \\
\text { Controle }\end{array}$ & $\begin{array}{l}\text { 'Público'b } \\
\text { 'Privado Nacional'c } \\
\text { 'Estrangeiro' }\end{array}$ & $\begin{array}{c}\text { Coluna 'Tipo de Controle', posição } \\
\text { ao final de cada semestre do relató- } \\
\text { rio ' } 50 \text { Maiores Bancos'. }\end{array}$ & $\begin{array}{l}\text { BCB (2011d); } \\
\text { Berger et al. (2005); } \\
\text { IBGC (2009). }\end{array}$ \\
\hline
\end{tabular}

Fonte: dados da pesquisa. Observações: ${ }^{\text {a. }}$ o atributo 'Ouvidoria - Outros e DDG' aglutinou os assuntos Ouvidoria Outros, Ouvidoria - Não Disponibilização de DDG e Ouvidoria - Não Divulgação de DDG;'. o atributo 'Público' aglutinou bancos públicos federais e estaduais; c. o atributo 'Privado Nacional' aglutinou bancos privados com e sem participação estrangeira e todas as aglutinações produziram atributos interpretáveis, baseados em Siegel e Castellan Jr. (2006); d. a segmentação do número de clientes em quartis atende a requisitos para execução da ACM e baseia-se em Carvalho (2008).

Para tratar os dados, empregou-se a estatística descritiva e a inferencial, mostrando-se, em tabelas de contingência, a distribuição do número de reclamações pertinentes às ouvidorias segundo atributos das variáveis do Quadro 3. Depois, verificou-se a associação de pares das variáveis por meio do Teste Qui-Quadrado (PESTANA; GAGEIRO, 2005). Por fim, empregou-se a $\mathrm{ACM}$, técnica multivariada de interdependência que permite a análise de "três ou mais variáveis categóricas relacionadas em um espaço perceptual comum" (HAIR JR. et al., 2009, p. 483).

Antes de executar a ACM, foi possível vincular um atributo de cada variável do Quadro 3 a cada ocorrência de reclamação pertinente à ouvidoria. A ACM submeteu esses dados qualitativos a um processo que estimou quantificações ótimas (optimal scaling) (TENENHAUS; YOUNG, 1985). Essas quantificações permitiram demonstrar, num espaço perceptual, as associações e as oposições entre os atributos de variáveis diferentes e entre os atributos de uma mesma variável. As quantificações permitiram, de forma complementar, ilustrar as ocorrências das 1.377 reclamações no referido espaço perceptual.

Considerando a revisão de literatura e estudos contemplando análise de dados históricos qualitativos (BENZÉCRI, 1992; GREENACRE, 2002; LIMA, 2007), foi possível identificar as dimensões estruturantes do espaço perceptual e as configurações de atributos nele ilustrados, baseado em Carvalho (2008). Para executar a ACM foi empregado o SPSS 15.0. As estatísticas, as tabelas e as figuras resultantes da ACM são mostradas na sequência.

\section{RESULTADOS}

Este capítulo mostra a análise dos resultados da pesquisa, cujo objetivo é demonstrar a evolução dos assuntos das reclamações pertinentes às ouvidorias, considerando o porte e o tipo de controle de bancos no Brasil. Apresenta-se a distribuição do número de reclamações (Seção 
4.1), ilustra-se a evolução dos assuntos reclamados (Seção 4.2) e conclui-se com a análise dos assuntos reclamados, considerando o porte e o tipo de controle (Seção 4.3).

\subsection{Distribuição do Número de Reclamações}

Esta seção aborda a distribuição do número de reclamações pertinentes às ouvidorias. Para tal fim, foram empregadas tabelas de contingência, contendo as variáveis citadas no Quadro 3 , e o resultado de associações entre pares de variáveis, verificado por meio de testes qui-quadrado (PESTANA; GAGEIRO, 2005).

A Tabela 1 mostra a distribuição das reclamações considerando as variáveis: Semestre e Assunto, Porte e Tipo de Controle. Na Tabela 1, o assunto 'Ouvidoria', constou de 427 reclamações no 2 ㅇ semestre de 2008 (100\% das reclamações do semestre). Os resultados dos testes, nessa tabela, mostraram associações entre pares de variáveis, significativas a $1 \%$, indicando que associações não foram aleatórias.

Tabela 1 - Distribuição das Reclamações: Semestre Versus Demais Variáveis

\begin{tabular}{|c|c|c|c|c|c|c|c|c|c|c|c|}
\hline \multirow[b]{2}{*}{ Variável } & \multirow[b]{2}{*}{$\begin{array}{c}\text { Atributos } \\
\text { da Variável }\end{array}$} & \multicolumn{7}{|c|}{ Semestre $^{a}$} & \multirow[b]{2}{*}{$\begin{array}{c}\text { Total } \\
(\%) \\
\end{array}$} & \multirow[b]{2}{*}{$\begin{array}{c}\text { Teste } \\
\text { Qui-quadrado }^{b}\end{array}$} & \multirow[b]{2}{*}{ g.l. } \\
\hline & & $\begin{array}{c}200801 \\
(\%)\end{array}$ & $\begin{array}{c}200802 \\
(\%)\end{array}$ & $\begin{array}{c}200901 \\
(\%)\end{array}$ & $\begin{array}{c}200902 \\
(\%)\end{array}$ & $\begin{array}{c}201001 \\
(\%)\end{array}$ & $\begin{array}{c}201002 \\
(\%)\end{array}$ & $\begin{array}{c}201101 \\
(\%)\end{array}$ & & & \\
\hline \multirow{4}{*}{ Assunto } & Ouvid & $\begin{array}{c}128 \\
(100,00 \%)\end{array}$ & $\begin{array}{c}427 \\
(100,00 \%)\end{array}$ & $\begin{array}{c}170 \\
(100,00 \%)\end{array}$ & $\begin{array}{c}23 \\
(23,96 \%)\end{array}$ & $\begin{array}{c}0 \\
(0,00 \%)\end{array}$ & $\begin{array}{c}0 \\
(0,00 \%)\end{array}$ & $\begin{array}{c}0 \\
(0,00 \%)\end{array}$ & $\begin{array}{c}748 \\
(54,32 \%)\end{array}$ & \multirow{4}{*}{$1842,48 * *$} & \multirow{4}{*}{18} \\
\hline & Dpr & $\begin{array}{c}0 \\
(0,00 \%)\end{array}$ & $\begin{array}{c}0 \\
(0,00 \%)\end{array}$ & $\begin{array}{c}0 \\
(0,00 \%)\end{array}$ & $\begin{array}{c}28 \\
(29,17 \%)\end{array}$ & $\begin{array}{c}133 \\
(59,91 \%)\end{array}$ & $\begin{array}{c}103 \\
(44,02 \%)\end{array}$ & $\begin{array}{c}17 \\
(17,00 \%)\end{array}$ & $\begin{array}{c}281 \\
(20,41 \%)\end{array}$ & & \\
\hline & Atd & $\begin{array}{c}0 \\
(0,00 \%)\end{array}$ & $\begin{array}{c}0 \\
(0,00 \%)\end{array}$ & $\begin{array}{c}0 \\
(0,00 \%)\end{array}$ & $\begin{array}{c}0 \\
(0,00 \%)\end{array}$ & $\begin{array}{c}31 \\
(13,96 \%)\end{array}$ & $\begin{array}{c}127 \\
(54,27 \%)\end{array}$ & $\begin{array}{c}75 \\
(75,00 \%)\end{array}$ & $\begin{array}{c}233 \\
(16,92 \%)\end{array}$ & & \\
\hline & Out_DDG & $\begin{array}{c}0 \\
(0,00 \%) \\
\end{array}$ & $\begin{array}{c}0 \\
(0,00 \%) \\
\end{array}$ & $\begin{array}{c}0 \\
(0,00 \%) \\
\end{array}$ & $\begin{array}{c}45 \\
(46,88 \%) \\
\end{array}$ & $\begin{array}{c}58 \\
(26,13 \%) \\
\end{array}$ & $\begin{array}{c}4 \\
(1,71 \%) \\
\end{array}$ & $\begin{array}{c}8 \\
(8,00 \%) \\
\end{array}$ & $\begin{array}{c}115 \\
(8,35 \%) \\
\end{array}$ & & \\
\hline \multirow{5}{*}{ Porte } & Pequeno & $\begin{array}{c}1 \\
(0,78 \%)\end{array}$ & $\begin{array}{c}75 \\
(17,56 \%)\end{array}$ & $\begin{array}{c}23 \\
(13,53 \%)\end{array}$ & $\begin{array}{c}6 \\
(6,25 \%)\end{array}$ & $\begin{array}{c}7 \\
(3,15 \%)\end{array}$ & $\begin{array}{c}22 \\
(9,40 \%)\end{array}$ & $\begin{array}{c}10 \\
(10,00 \%)\end{array}$ & $\begin{array}{c}144 \\
(10,46 \%)\end{array}$ & \multirow{5}{*}{$349,88^{*} *$} & \multirow{5}{*}{18} \\
\hline & Médio & $\begin{array}{c}70 \\
(54,69 \%)\end{array}$ & $\begin{array}{c}268 \\
(62,76 \%)\end{array}$ & $\begin{array}{c}43 \\
(25,29 \%)\end{array}$ & $\begin{array}{c}54 \\
(56,25 \%)\end{array}$ & $\begin{array}{c}138 \\
(62,16 \%)\end{array}$ & $\begin{array}{c}76 \\
(32,48 \%)\end{array}$ & $\begin{array}{c}37 \\
(37,00 \%)\end{array}$ & $\begin{array}{c}686 \\
(49,82 \%)\end{array}$ & & \\
\hline & Grande & $\begin{array}{c}36 \\
(28,13 \%)\end{array}$ & $\begin{array}{c}19 \\
(4,45 \%)\end{array}$ & $\begin{array}{c}2 \\
(1,18 \%)\end{array}$ & $\begin{array}{c}4 \\
(4.17 \%)\end{array}$ & $\begin{array}{c}1 \\
(0,45 \%)\end{array}$ & $\begin{array}{c}21 \\
(8,97 \%)\end{array}$ & $\begin{array}{c}2 \\
(2,00 \%)\end{array}$ & $\begin{array}{c}85 \\
(6,17 \%)\end{array}$ & & \\
\hline & Muito & 21 & 65 & 102 & 32 & 76 & 115 & 51 & 462 & & \\
\hline & Grande & $(16,41 \%)$ & $(15,22 \%)$ & $(60,00 \%)$ & $(33,33 \%)$ & $(34,23 \%)$ & $(49,15 \%)$ & $(51,00 \%)$ & $(33,55 \%)$ & & \\
\hline \multirow{3}{*}{$\begin{array}{l}\text { Tipo de } \\
\text { Controle }\end{array}$} & Público & $\begin{array}{c}19 \\
(14,84 \%)\end{array}$ & $\begin{array}{c}45 \\
(10,54 \%)\end{array}$ & $\begin{array}{c}86 \\
(50,59 \%)\end{array}$ & $\begin{array}{c}24 \\
(25,00 \%)\end{array}$ & $\begin{array}{c}67 \\
(30,18 \%)\end{array}$ & $\begin{array}{c}70 \\
(29,91 \%)\end{array}$ & $\begin{array}{c}20 \\
(20,00 \%)\end{array}$ & $\begin{array}{c}331 \\
(24,04 \%)\end{array}$ & \multirow{3}{*}{$133,95 * *$} & \multirow{3}{*}{12} \\
\hline & $\begin{array}{c}\text { Privado } \\
\text { Nacional }\end{array}$ & $\begin{array}{c}103 \\
(80,47 \%)\end{array}$ & $\begin{array}{c}369 \\
(86,42 \%)\end{array}$ & $\begin{array}{c}79 \\
(46,47 \%)\end{array}$ & $\begin{array}{c}67 \\
(69,79 \%)\end{array}$ & $\begin{array}{c}153 \\
(68,92 \%)\end{array}$ & $\begin{array}{c}160 \\
(68,38 \%)\end{array}$ & $\begin{array}{c}74 \\
(74,00 \%)\end{array}$ & $\begin{array}{c}1005 \\
(72,98 \%)\end{array}$ & & \\
\hline & Estrangeiro & $\begin{array}{c}6 \\
(4,69 \%) \\
\end{array}$ & $\begin{array}{c}13 \\
(3,04 \%) \\
\end{array}$ & $\begin{array}{c}5 \\
(2,94 \%) \\
\end{array}$ & $\begin{array}{c}5 \\
(5,21 \%) \\
\end{array}$ & $\begin{array}{c}2 \\
(0,90 \%) \\
\end{array}$ & $\begin{array}{c}4 \\
(1,71 \%) \\
\end{array}$ & $\begin{array}{c}6 \\
(6,00 \%) \\
\end{array}$ & $\begin{array}{c}41 \\
(2,98 \%) \\
\end{array}$ & & \\
\hline
\end{tabular}

Fonte: dados da pesquisa. Legenda: 'Ouvid' indica Ouvidoria; 'Dpr' indica Descumprimento de prazo; 'Atd' indica Atendimento; 'Out_DDG' indica Outros e DDG; 'g.l.' indica graus de liberdade. Observações: a. Para cada semestre, percentuais devem ser totalizados na vertical e referem-se às frequências observadas dos atributos de cada variável

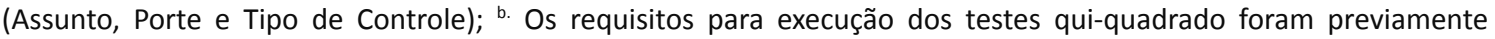
atendidos (SIEGEL; CASTELLAN JR, 2006). $+p<0,10 ;{ }^{*} p<0,05 ;{ }^{* *} p<0,01$.

A Tabela 2 mostra a distribuição das reclamações, comparando o assunto reclamado às variáveis Porte e Tipo de Controle. Essas duas variáveis foram apresentadas na revisão de literatura (Seção 2.4) como variáveis de governança corporativa (IBGC, 2009). Os bancos com controle privado nacional receberam 232 reclamações, cujo assunto foi 'Descumprimento de Prazo' (82,56\% das reclamações do referido assunto). Os resultados dos testes evidenciaram associações entre pares de variáveis, no nível de significância de $1 \%$, indicando que as associações não foram aleatórias. 
Tabela 2 - Distribuição das Reclamações: Assunto Versus Variáveis de Governança

\begin{tabular}{|c|c|c|c|c|c|c|c|c|}
\hline \multirow[b]{2}{*}{ Variável } & \multirow[b]{2}{*}{$\begin{array}{c}\text { Atributos } \\
\text { da Variável }\end{array}$} & \multicolumn{4}{|c|}{ Assunto $^{a}$} & \multirow[b]{2}{*}{$\begin{array}{l}\text { Total } \\
(\%)\end{array}$} & \multirow[b]{2}{*}{$\begin{array}{c}\text { Teste } \\
\text { Qui-quadrado }\end{array}$} & \multirow[b]{2}{*}{ g.l } \\
\hline & & $\begin{array}{c}\text { Ouvid } \\
(\%)\end{array}$ & $\begin{array}{l}\text { Dpr } \\
(\%)\end{array}$ & $\begin{array}{l}\text { Atd } \\
(\%)\end{array}$ & $\begin{array}{c}\text { Out_DDG } \\
(\%)\end{array}$ & & & \\
\hline \multirow{4}{*}{ Porte } & Pequeno & $\begin{array}{c}101 \\
(13,50 \%)\end{array}$ & $\begin{array}{c}25 \\
(8,90 \%)\end{array}$ & $\begin{array}{c}14 \\
(6,01 \%)\end{array}$ & $\begin{array}{c}4 \\
(3,48 \%)\end{array}$ & $\begin{array}{c}144 \\
(10,46 \%)\end{array}$ & \multirow{4}{*}{$190,73^{* *}$} & \multirow{4}{*}{9} \\
\hline & Médio & $\begin{array}{c}388 \\
(51,87 \%)\end{array}$ & $\begin{array}{c}183 \\
(65,12 \%)\end{array}$ & $\begin{array}{c}52 \\
(22,32 \%)\end{array}$ & $\begin{array}{c}63 \\
(54,78 \%)\end{array}$ & $\begin{array}{c}686 \\
(49,82 \%)\end{array}$ & & \\
\hline & Grande & $\begin{array}{c}58 \\
(7,75 \%)\end{array}$ & $\begin{array}{c}18 \\
(6,41 \%)\end{array}$ & $\begin{array}{c}7 \\
(3,00 \%)\end{array}$ & $\begin{array}{c}2 \\
(1,74 \%)\end{array}$ & $\begin{array}{c}85 \\
(6,17 \%)\end{array}$ & & \\
\hline & $\begin{array}{l}\text { Muito } \\
\text { Grande }\end{array}$ & $\begin{array}{c}201 \\
(26,87 \%) \\
\end{array}$ & $\begin{array}{c}55 \\
(19,57 \%)\end{array}$ & $\begin{array}{c}160 \\
(68,67 \%) \\
\end{array}$ & $\begin{array}{c}46 \\
(40,00 \%)\end{array}$ & $\begin{array}{c}462 \\
(33,55 \%)\end{array}$ & & \\
\hline \multirow{3}{*}{$\begin{array}{l}\text { Tipo de } \\
\text { Controle }\end{array}$} & Público & $\begin{array}{c}158 \\
(21,12 \%)\end{array}$ & $\begin{array}{c}43 \\
(15,30 \%)\end{array}$ & $\begin{array}{c}99 \\
(42,49 \%)\end{array}$ & $\begin{array}{c}31 \\
(26,96 \%)\end{array}$ & $\begin{array}{c}331 \\
(24,04 \%)\end{array}$ & \multirow{3}{*}{$61,93 * *$} & \multirow{3}{*}{6} \\
\hline & $\begin{array}{l}\text { Privado } \\
\text { Nacional }\end{array}$ & $\begin{array}{c}564 \\
(75,40 \%)\end{array}$ & $\begin{array}{c}232 \\
(82,56 \%)\end{array}$ & $\begin{array}{c}127 \\
(54,51 \%)\end{array}$ & $\begin{array}{c}82 \\
(71,30 \%)\end{array}$ & $\begin{array}{c}1005 \\
(72,98 \%)\end{array}$ & & \\
\hline & Estrangeiro & $\begin{array}{c}26 \\
(3,48 \%) \\
\end{array}$ & $\begin{array}{c}6 \\
(2,14 \%) \\
\end{array}$ & $\begin{array}{c}7 \\
(3,00 \%)\end{array}$ & $\begin{array}{c}2 \\
(1,74 \%) \\
\end{array}$ & $\begin{array}{c}41 \\
(2,98 \%) \\
\end{array}$ & & \\
\hline
\end{tabular}

Fonte: dados da pesquisa. Legenda: 'Ouvid' indica Ouvidoria; 'Dpr' indica Descumprimento de prazo; 'Atd' indica Atendimento; 'Out_DDG' indica Outros e DDG; 'g.l.' indica graus de liberdade. Observações: a. Para cada assunto, percentuais devem ser totalizados na vertical e referem-se às frequências observadas dos atributos de cada variável

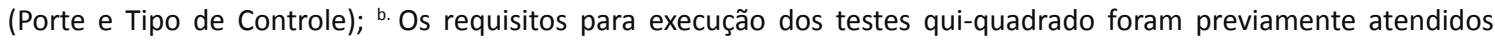
(SIEGEL; CASTELLAN JR, 2006). $+p<0,10 ; * p<0,05 ; * *<<0,01$.

A Tabela 3 apresenta a distribuição das reclamações, comparando as variáveis, Porte e Tipo de Controle. Apurou-se que 686 reclamações foram vinculadas a bancos com controle privado nacional e de porte médio ( $100 \%$ das reclamações do referido porte). O resultado do teste indicou associação entre o par de variáveis, no nível de significância de $1 \%$, denotando que essa associação não foi aleatória.

O número de reclamações registradas no $\mathrm{BCB}$ foi citado na revisão de literatura como uma prova das ações socialmente responsáveis de bancos associada à melhoria do atendimento (CRUVINEL, 2008). Os resultados apresentados nas Tabelas 1 a 3 evidenciaram a distribuição do número de reclamações, indicando que as associações entre pares de variáveis não foram aleatórias. Sem prejuízo dessa constatação, o exame da evolução dos assuntos reclamados, na Seção 4.2, traz evidências adicionais a respeito desse atendimento.

Tabela 3 - Distribuição das Reclamações: Porte Versus Tipo de Controle

\begin{tabular}{|c|c|c|c|c|c|c|c|c|}
\hline \multirow[b]{2}{*}{ Variável } & \multirow[b]{2}{*}{$\begin{array}{c}\text { Atributos } \\
\text { da Variável }\end{array}$} & \multicolumn{4}{|c|}{ Porte $^{a}$} & \multirow[b]{2}{*}{$\begin{array}{l}\text { Total } \\
(\%)\end{array}$} & \multirow[b]{2}{*}{$\begin{array}{c}\text { Teste } \\
\text { Qui-quadrado }^{b}\end{array}$} & \multirow[b]{2}{*}{ g.l. } \\
\hline & & $\begin{array}{c}\text { Pequeno } \\
(\%)\end{array}$ & $\begin{array}{l}\text { Médio } \\
(\%)\end{array}$ & $\begin{array}{c}\text { Grande } \\
(\%)\end{array}$ & $\begin{array}{c}\text { Muito } \\
\text { Grande } \\
(\%) \\
\end{array}$ & & & \\
\hline \multirow{4}{*}{$\begin{array}{l}\text { Tipo de } \\
\text { Controle }\end{array}$} & Público & $\begin{array}{c}0 \\
(0,00 \%)\end{array}$ & $\begin{array}{c}0 \\
(0,00 \%)\end{array}$ & $\begin{array}{c}2 \\
(2,35 \%)\end{array}$ & $\begin{array}{c}329 \\
(71,21 \%)\end{array}$ & $\begin{array}{c}331 \\
(24,04 \%)\end{array}$ & \multirow{4}{*}{$976,05 * *$} & \multirow{4}{*}{6} \\
\hline & Privado & 143 & 686 & 68 & 108 & 1005 & & \\
\hline & Nacional & $(99,31 \%)$ & $(100,00 \%)$ & $(80,00 \%)$ & $(23,38 \%)$ & $(72,98 \%)$ & & \\
\hline & Estrangeiro & $\begin{array}{c}1 \\
(0,69 \%)\end{array}$ & $\begin{array}{c}0 \\
(0,00 \%)\end{array}$ & $\begin{array}{c}15 \\
(17,65 \%)\end{array}$ & $\begin{array}{c}25 \\
(5,41 \%)\end{array}$ & $\begin{array}{c}41 \\
(2,98 \%)\end{array}$ & & \\
\hline
\end{tabular}

Fonte: dados da pesquisa. Legenda: 'g.l.' são graus de liberdade. Observações: ${ }^{\text {a. }}$ Para cada porte, percentuais devem ser totalizados na vertical e referem-se às frequências observadas de cada atributo da variável Tipo de Controle; ${ }^{\text {b. Os }}$ requisitos para execução do teste qui-quadrado foram previamente atendidos (SIEGEL; CASTELLAN JR, 2006). $+p<$ 0,$1 ; *<0,05$; $^{* *} p<0,01$. 


\subsection{Evolução dos Assuntos das Reclamações}

Para demonstrar a evolução dos assuntos das reclamações pertinentes às ouvidorias, empregou-se a ACM, citada no Capítulo 3. Por meio de um processo de quantificação, a ACM reduziu a dimensionalidade dos dados descritos nas Tabelas 1 a 3, permitindo a análise dos atributos das variáveis num espaço perceptual. Os resultados mostram a identificação das dimensões que estruturam esse espaço perceptual e a identificação das configurações de atributos das variáveis no referido espaço. Neste estudo, "a noção de dimensão é definida pela possibilidade de fixar, sem ambiguidade nem redundância, os pontos de certo número de coordenadas" (BENZÉCRI, 1992, p. 19).

Inicialmente, das 14 dimensões identificadas, as duas primeiras com maiores inércias apresentaram valores 0,75 e 0,62 para o Alfa de Cronbach, respectivamente, permitindo privilegiar essas duas dimensões nas análises seguintes. Nesta pesquisa, o Alfa de Cronbach é uma medida estatística de confiabilidade (CRONBACH, 1951), empregada para indicar o ajuste por dimensão (Carvalho, 2008). A medida varia de 0 a 1, tendo o limite inferior aceitável de 0,70, apesar de poder diminuir para 0,60 em pesquisa exploratória (HAIR JR. et al., 2009).

Para a 1ㅁ dimensão, os percentuais de variância explicada das variáveis de governança (Porte e Tipo de Controle) totalizaram mais de $50,00 \%$ da variância explicada. Assim, optou-se por nomear a 1a dimensão de 'Predomínio dos Atributos das Variáveis de Governança'. Para a 2a dimensão, os percentuais de variância explicada das variáveis Semestre e Assunto totalizaram mais de 75,00\% da variância explicada, optando-se por nomear a 2a dimensão de 'Predomínio do Perfil Histórico dos Assuntos das Reclamações'. A Figura 1 ilustra o espaço perceptual.

A Figura 1 possui quatro quadrantes com cinco configurações (de $A$ até $E$ ), as quais privilegiam associações entre atributos das variáveis. A identificação das configurações considerou atributos representativos, os quais contribuíram para a inércia das dimensões acima da contribuição média (PESTANA; GAGEIRO, 2005). Os atributos '200901' e 'Estrangeiro', apesar de próximos, não integraram uma configuração porque o atributo 'Estrangeiro' não foi representativo para as dimensões. Também não foram representativos os atributos 'Pequeno', 'Grande', '200801', '200902' e '201101'.

A Figura 1 mostra uma linha unindo os atributos da variável ordinal Semestre (GREENACRE, 2002). Essa linha orienta a narrativa cronológica a respeito das configurações, abrangendo semestres e assuntos reclamados. Verifica-se que entre o 1ㅇs semestre de 2008 e o 10 semestre de 2009, a linha percorre a parte inferior do espaço perceptual. Nesses semestres predominou 0 assunto 'Ouvidoria'. Constata-se a Configuração D, no 3ㅇ quadrante da Figura 1, privilegiando a associação do assunto 'Ouvidoria' ao 20 semestre de 2008. O assunto 'Ouvidoria' apresentou 427 reclamações no 20 semestre de 2008 (vide Tabela 1).

Entre o 1으 e o 2으 semestres de 2009 a trajetória da linha segue do 4으 para o 1ㅇquadrante da Figura 1 onde consta a Configuração B. Essa configuração privilegia a associação entre os assuntos 'Outros e DDG', 'Descumprimento de Prazo' e o 1ㅇ semestre de 2010. Segundo a revisão de literatura, no 1 - semestre de 2010 o prazo de resposta regulamentar das ouvidorias foi de 30 para 15 dias (CMN, 2007a, 2010).

Verifica-se que o 2 ㅇ semestre de 2010 e o 1ㅇ semestre de 2011 foram mais condicionados ao assunto 'Atendimento'. Constata-se a Configuração A, privilegiando associação entre esse assunto e o 20 semestre de 2010. O assunto 'Atendimento' constou de 127 reclamações no 20 semestre de 2010, correspondente a 54,27\% do total de reclamações desse semestre (conforme Tabela 1). 
Figura 1 - Configurações de Atributos das Variáveis no Espaço Perceptual

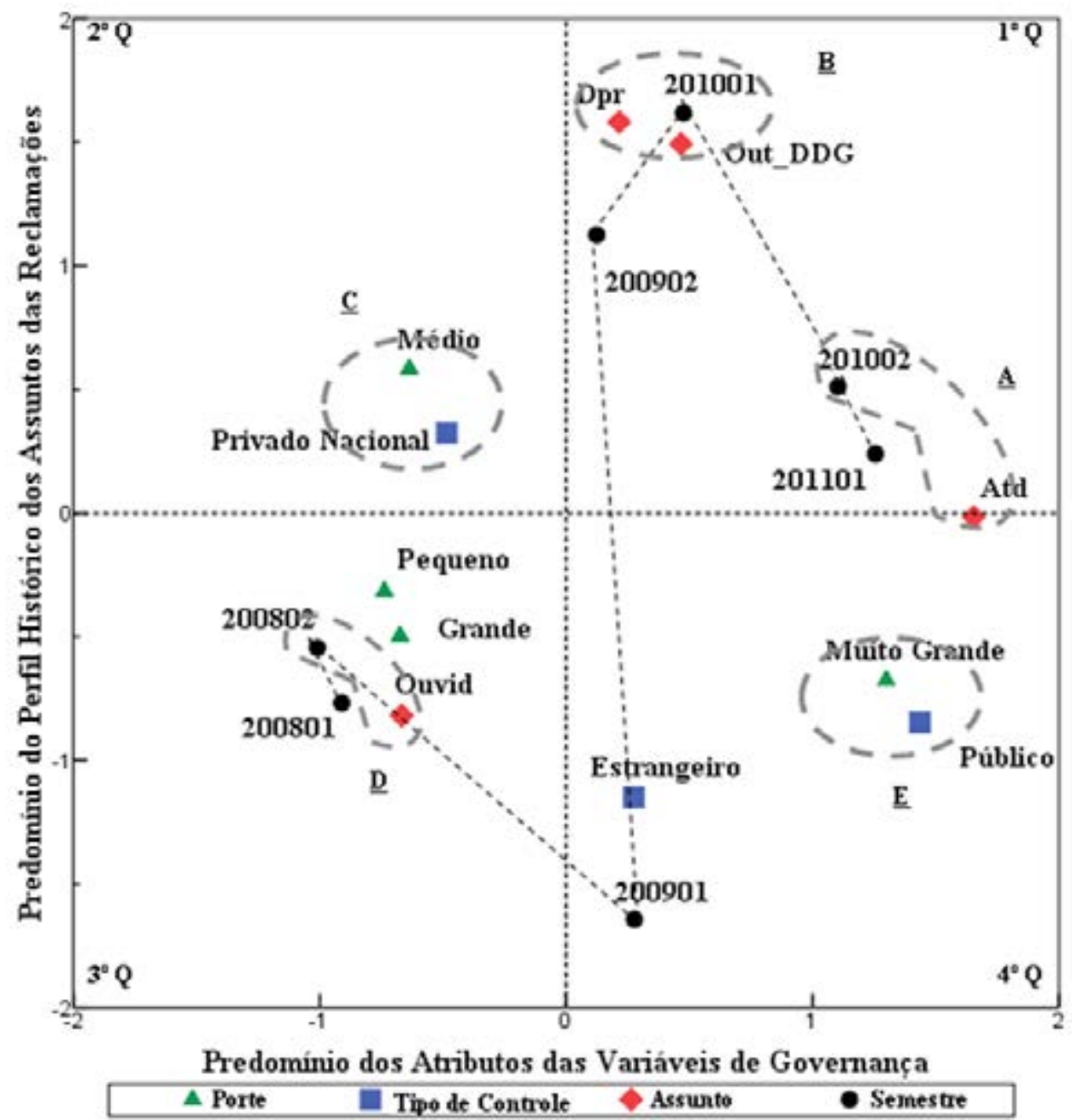

Fonte: dados da pesquisa. Legenda: '1으 $Q$ ' ao ' 4 으 $Q$ ' indica do 1ㅇ ao 4을 quadrante; letras de 'A' a ' $E$ ', ordenadas por quadrante, indicam as configurações privilegiadas no espaço perceptual; linha tracejada unindo os semestres ilustra a evolução do assunto reclamado; 'Ouvid' significa Ouvidoria; 'Out_DDG' significa Outros e DDG; 'Dpr' significa Descumprimento de Prazo; 'Atd' significa Atendimento.

A Figura 2 ilustra as ocorrências de reclamações pertinentes às ouvidorias. Foram identificadas as ocorrências encerradas nos três primeiros semestres da análise (até o 10 semestre de 2009) e nos quatro semestres finais da análise (a partir do 2 으 semestre de 2009). O entendimento da Figura 2 complementa as análises das configurações dos atributos porque é uma forma de ilustrar a topologia das ocorrências de reclamações que deram base às projeções desses atributos no espaço perceptual mostrado na Figura 1. 
Figura 2 - Ocorrências de Reclamações no Espaço Perceptual ${ }^{a}$

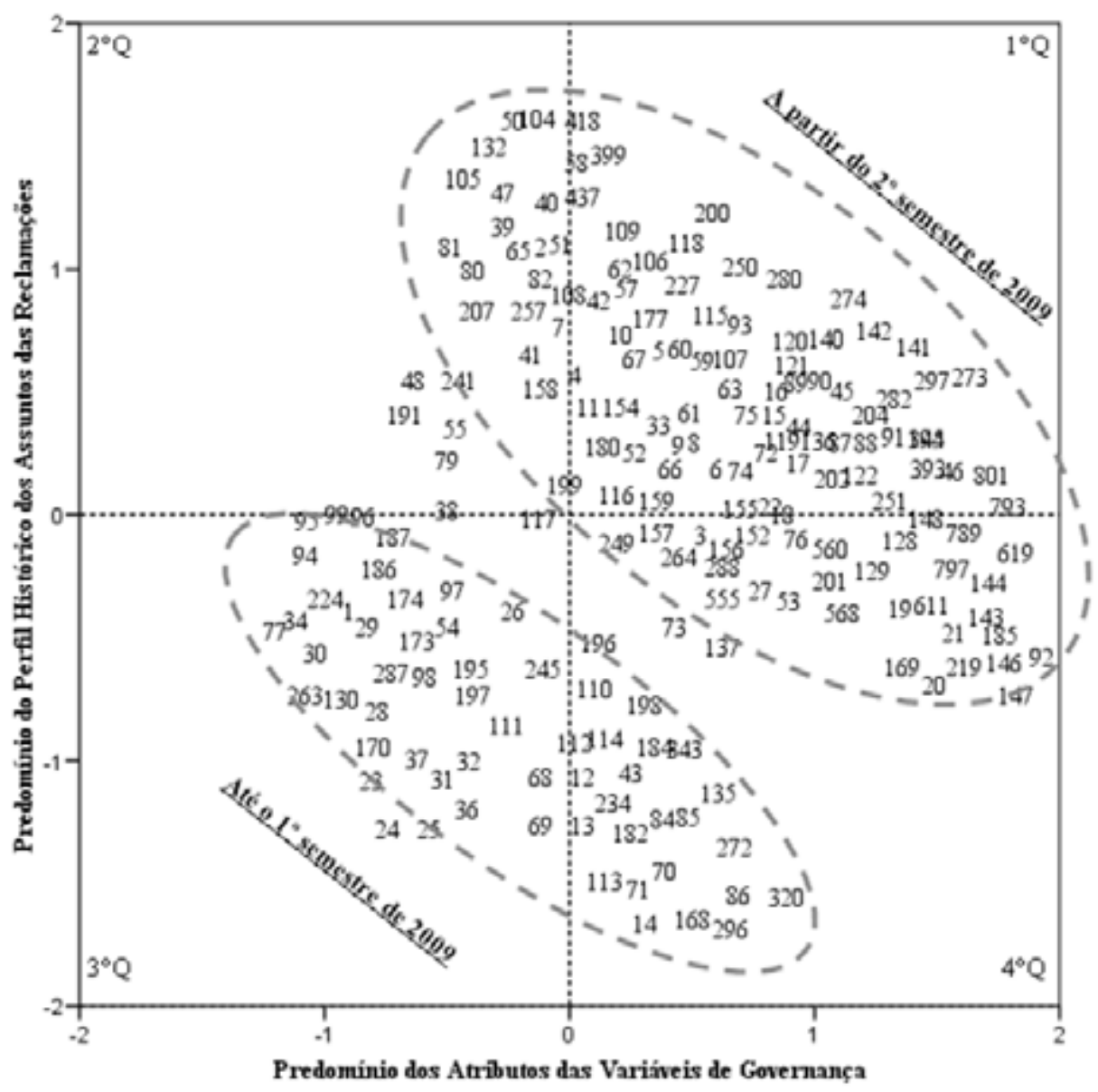

Fonte: dados da pesquisa. Legenda: '10 Q' ao ‘4o $Q$ ' indica 10 ao 4ㅇq quadrante. Observação: a. Numeração indica as ocorrências de reclamações, podendo haver ocorrências sobrepostas numa mesma coordenada do espaço perceptual.

A revisão de literatura citou pesquisas que vincularam o estudo das reclamações à responsabilidade social corporativa de bancos (HINSON; BOATENG; MADICHIE, 2010; YEUNG, 2011) e o número de reclamações registradas no $B C B$ foi mostrado nessa revisão como uma prova das ações socialmente responsáveis de bancos associada à melhoria do atendimento (CRUVINEL, 2008). A distribuição do número de reclamações foi apresentada na Seção 4.1 e, adicionalmente, nesta seção apresentaram-se análises dos assuntos reclamados. Assim, os resultados apresentados contribuem para ampliar o entendimento a respeito da implementação das ações socialmente responsáveis de bancos para atender os stakeholders clientes e usuários no Brasil.

\subsection{Análise dos Assuntos Reclamados Considerando o Porte e o Tipo de Controle}

A Figura 1 evidencia duas configurações específicas entre os atributos das variáveis porte e tipo de controle dos bancos. A primeira delas (Configuração $\mathrm{C}$ ) privilegia a associação entre bancos de porte médio que possuem controle privado nacional, no $2^{\circ}$ quadrante, e opõe-se à Configuração $E$, que privilegia a associação entre bancos de porte muito grande que possuem controle público, no 4ㅇ quadrante. A oposição entre essas duas configurações de atributos permitiu condicioná-las, por proximidade, a assuntos reclamados específicos. 
Baseado na Figura 1, os assuntos 'Descumprimento de Prazo' e 'Outros e DDG' estiveram mais condicionados às reclamações de bancos de porte médio e com controle privado nacional (Configuração $C$ ) do que às reclamações de bancos de porte muito grande e com controle público (Configuração E). Por sua vez, o assunto 'Atendimento' foi mais condicionado às reclamações de bancos muito grandes em termos de clientela e com controle público (Configuração E) do que às reclamações de bancos de porte médio e com controle privado nacional (Configuração $\mathrm{C}$ ).

Adicionalmente, foi possível constatar que o assunto 'Ouvidoria' mostrou condicionamento aos atributos das configurações $\mathrm{C}$ e $\mathrm{E}$, com maior proximidade aos atributos da Configuração C. Conforme a Seção 4.2, os atributos 'Estrangeiro', 'Pequeno' e 'Grande' não integraram uma configuração porque não foram representativos para definir as dimensões da Figura 1.

A introdução e a revisão de literatura mostraram que as ouvidorias são obrigatórias, independente do porte ou do tipo de controle do banco (CMN, 2010). Baseado nas análises englobando as configurações $\mathrm{C}$ e $\mathrm{E}$, os resultados sugerem que os assuntos reclamados foram condicionados a bancos com diferentes portes e diferentes tipos de controle. Tais achados podem ser usados na avaliação de políticas relativas às atribuições regulamentares de ouvidorias em bancos no Brasil, considerando, nessa avaliação, atributos das variáveis de governança corporativa citadas na Seção 2.4 da revisão de literatura, as quais são baseadas em práticas recomendadas pelo IBGC.

\section{CONCLUSÃO}

Este estudo buscou demonstrar a evolução dos assuntos das reclamações pertinentes às ouvidorias dos bancos, considerando o porte e o tipo de controle no Brasil. Tratou-se um tema atual e pouco explorado, considerando que as ouvidorias estão entre os mecanismos para solucionar conflitos no setor bancário envolvendo clientes e usuários. Tais mecanismos são lembrados em princípios recomendados para proteção do consumidor de produtos financeiros disseminados internacionalmente pela OECD.

Quanto à distribuição do número de reclamações, segmentada pelas variáveis: porte, tipo de controle, assunto e semestre, os resultados de associações entre pares de variáveis, verificado por meio de testes qui-quadrado, mostraram significância a $1 \%$, indicando que associações não foram aleatórias. O assunto 'Ouvidoria' constou de 427 reclamações no 2 ㅇ semestre de 2008 (100\% das reclamações do semestre), os bancos com controle privado nacional receberam 232 reclamações, cujo assunto foi 'Descumprimento de Prazo' (82,56\% das reclamações do referido assunto), e apurou-se que 686 reclamações foram vinculadas a bancos com controle privado nacional e de porte médio ( $100 \%$ das reclamações do referido porte).

Constatou-se que as atribuições das ouvidorias não foram implementadas de maneira uniforme no período analisado, visto que diferentes assuntos reclamados prevaleceram em diferentes semestres. Foi possível, dessa forma, segmentar as ocorrências de reclamações encerradas até o 1 을 semestre de 2009, nas quais o assunto 'Ouvidoria' prevaleceu (especialmente no 20 semestre de 2008), daquelas ocorrências de reclamações encerradas a partir do 20 semestre de 2009, nas quais outros assuntos reclamados prevaleceram. No 10 semestre de 2010 prevaleceram os assuntos 'Descumprimento de Prazo' e 'Outros e DDG', e no 20 semestre de 2010 prevaleceu o assunto 'Atendimento'.

O número de reclamações registradas no $B C B$ foi apresentado na revisão de literatura como uma prova das ações socialmente responsáveis de bancos associada à melhoria do atendimento. Os resultados obtidos neste estudo evidenciaram, além da distribuição do número de reclamações, a evolução dos assuntos dessas reclamações. Assim, os resultados podem contribuir 
para que acadêmicos, reguladores, acionistas e demais interessados possam melhor entender a implementação das ações socialmente responsáveis de bancos para atender os stakeholders clientes e usuários no Brasil.

Adicionalmente, os assuntos reclamados foram condicionados a bancos com diferentes portes e tipos de controle. Os assuntos 'Descumprimento de Prazo' e 'Outros e DDG' foram mais condicionados aos bancos de porte médio e com controle privado nacional. Por sua vez, o assunto 'Atendimento' foi mais condicionado aos bancos de porte muito grande e com controle público. Tais achados podem ser considerados em avaliações de políticas relativas às atribuições regulamentares das ouvidorias desses bancos no Brasil, considerando, nessa avaliação, os atributos de variáveis baseadas em práticas recomendadas pelo IBGC.

Quanto ao aspecto metodológico, este trabalho mostrou uma aplicação original da técnica ACM, usada para auxiliar a interpretação de dados qualitativos a respeito das ocorrências de reclamações no setor bancário brasileiro. A referida técnica multivariada reduziu a dimensionalidade dos dados descritos em tabelas de contingência, apresentadas nas análises dos resultados.

Quanto às limitações desta pesquisa, a técnica ACM não permite inferir tendências, mas como foi usada para tratar os dados de forma exploratória, num período já ocorrido, essa limitação não interferiu no alcance do objetivo deste estudo. Adicionalmente, as interpretações dos resultados consideraram a legislação e a regulamentação vigentes no período a que se referem os dados coletados. Em complemento, as razões para apresentar reclamações a bancos ou a terceiros referem-se a estudos do comportamento do consumidor diante de reclamações e não fizeram parte do foco desta pesquisa.

Por fim, a variável assunto, apresentada no Quadro 3 deste artigo, pode ser aproveitada em outras pesquisas acadêmicas. Como recomendações para estudos futuros, pode-se estudar a evolução dos assuntos das reclamações pertinentes às ouvidorias em diferentes períodos ou empregando técnicas multivariadas de natureza confirmatória, confrontando os resultados com os desta pesquisa. Pode-se, ainda, analisar outros assuntos das reclamações apresentadas ao BCB ou a outras entidades, como os Procons, buscando o aperfeiçoamento das ações socialmente responsáveis de bancos para atender seus stakeholders no País.

\section{REFERENCIAS}

AKANBI, P. A; OFOEGBU, O. E. Impact of corporate social responsibility on bank performance in Nigeria. Journal of US-China Public Administration. v. 9, n. 4, p. 374-383, 2012.

ALVES, C. A. M.; MACHADO FILHO, C. A. P. Os princípios de governança corporativa e a atuação das ouvidorias em instituições bancárias no Brasil. GEPROS. Gestão da Produção, Operações e Sistemas, Bauru, v. 9, n. 2, p. 51-63, 2014.

BCB. BANCO CENTRAL DO BRASIL. Circular 3.289, de 31 de agosto de 2005. Disponível em: http://www.bcb.gov.br/pre/normativos/ circ/2005/pdf/circ_3289_v1_O.pdf. Acesso em: 02.01.2013.

\section{Fundo Garantidor de Crédito.}

Disponivel em: http://www.bcb.gov.br/pre/ bc__atende/port/fgc.asp?idpai=portalbcb. Acesso em: 20.12.2011a.

Ouvidorias dos bancos. Disponível em: http://www.bcb. gov.br/?OUVIDBANCOS. Acesso em: 30.06.2011b.

Ranking de instituições mais reclamadas. Disponível em: http://www.bcb. gov.br/ ?RANKING. Acesso em: 30.07.2011c.

Relatório 50 maiores bancos e o consolidado do Sistema Financeiro Nacional. 
Data base junho de 2011d. Disponível em: http:// www.bcb.gov.br. Acesso em: 20.12.2011.

Edital de audiência pública 41/2012, de 13 de junho de 2012a. Disponível em: http:// www.bcb.gov.br. Acesso em: 01.07.2013.

Publicações editadas pelo Banco Central do Brasil - Critérios Adotados. Disponível em: http://www4.bcb.gov.br/ pre/ranking/port/criterios.asp. Acesso em: 30.07.2012b.

BCBS. BASEL COMMITTEE ON BANKING SUPERVISION. Enhancing corporate governance for banking organizations. Bank for International Settlements, September, 1999. Disponível em: http://www.bis.org/ publ/ bcbs56.pdf. Acesso em: 02.04.2012.

Customer suitability in the retail sale of financial products and services. The Joint Forum, Bank for International Settlements, April, 2008. Disponível em: http://www. bis. org/publ/joint20.pdf. Acesso em: 03.10.2009.

BENZÉCRI, J. P. Correspondence analysis handbook. New York: Marcel Dekker Inc, 1992.

BERGER, A. N. et al. Corporate governance and bank performance: a joint analysis of the static, selection, and dynamic effects of domestic, foreign, and state ownership. World Bank Policy Research Working Paper, n. 3632, June 2005. Disponível em: < https:// openknowledge. worldbank.org/handle/10986/8229 >. Acesso em: 02.08.2012.

CARROLL, A. B. A three-dimensional conceptual model of corporate performance. The Academy of Management Review, v.4, p. 497-505, 1979.

CARVALHO, $\mathrm{H}$. Análise multivariada de dados qualitativos - utilização da análise de correspondências múltiplas com o SPSS. Lisboa: Sílabo, 2008.

CLARKSON, M. B. E. A stakeholder framework for analyzing and evaluating corporate social performance. The Academy of Management Review, v. 20, n. 1, p. 92-117, 1995.

CMN. CONSELHO MONETÁRIO NACIONAL. Resolução $n^{\circ}$ 3.477, de 26 de julho de 2007a (Revogada). Disponível em: https://www3.bcb. gov.br/ normativo/detalharNormativo. do? method= detalhar Normativo\&N=107238413. Acesso em: 03.11.2009.

. Resolução $n^{\circ}$ 3.489, de 29 de agosto de 2007b (Revogada). Disponível em: http:// www.bcb.gov.br. Acesso em: 5.11.2009.

. Resolução $n^{\circ}$ 3.849, de 25 de março

de 2010. Disponível em: http://www.bcb.gov. br. Acesso em: 26.04.2010.

CRIÉ, D. Consumer's complaint behaviour. Taxonomy, typology and determinants: towards a unified ontology. Database Marketing \& Consumer Strategy Management, v.11, n.1, p. 60-79, 2003.

CRONBACH, L. J. Coefficient Alpha and the internal structure of tests. Psychometrika, v. 16, n. 3, p. 297-334, 1951.

CRUVINEL, E. Responsabilidade social em instituições financeiras: a institucionalização da prática nos bancos no Brasil. Rio de Janeiro: Elsevier, 2008.

DANET, B. Toward a method to evaluate the ombudsman role. Administration \& Society, v. 10, n. 3, p.335-369, 1978.

DICK, A. A. Demand estimation and consumer welfare in the banking industry. Journal of Banking \& Finance, v. 32, p. 1661-1676, 2008.

FOMBRUN, C. J.; GARDBERG, N. A.; BARNETT, M. L. Opportunity platforms and safety nets: corporate citizenship and reputational risk. Business and Society Review, v. 105, n.1, p. 85-106, 2000.

FREEMAN, E. R. The politics of stakeholder theory: some futures directions. Business 
Ethics Quarterly, v.4, n.4, p.409-421, 1994.

GREENACRE, M. J. Correspondence analysis of the spanish national health survey. Gaceta Sanitaria, v. 16, n. 2, p. 60-170, 2002.

HAIR JR et. al. Análise multivariada de dados. 6 ed. Porto Alegre: Bookman, 2009.

HINSON, R. BOATENG, R.; MADICHIE, N. Corporate social responsibility activity reportage on bank websites in Ghana. International Journal of Bank Marketing. v. 28, n. 7, p. 498-518, 2010.

HIRSCHMAN, A. O. Saída, voz e lealdade. Reações ao declínio de firmas, organizações e Estados. São Paulo: Perspectiva, 1970.

IBGC. INSTITUTO BRASILEIRO DE GOVERNANÇA CORPORATIVA. Código de melhores práticas de governança corporativa. 4 ed. São Paulo: IBGC, 2009.

LIMA, G. A. S. F. de. Utilização da teoria da divulgação para avaliação da relação do nível de disclosure com o custo da dívida das empresas brasileiras. 2007, 108p. Tese (Doutorado em Ciências Contábeis), Departamento de Contabilidade e Atuária FEA-USP. São Paulo, 2007.

LLIEHAUSEN, G.E., WOLKEN, J.D. Banking Markets and the use of Financial Services by Small and Medium-Sized Businesses. Federal Reserve Bulletin, 801-817, 1990.

MACHADO FILHO, C. A. P. Responsabilidade social e governança: o debate e as implicações. São Paulo: Thomson, 2006.

MACHADO FILHO, C. A. P; ZYLBERSTAJN, D. A. Empresa socialmente responsável: o debate e as implicações. Revista de Administração, v.39, n.3, p.242-254, 2004.

MILANI, B.; CERETTA, P. S. Efeito Tamanho nos Fundos de Investimento Brasileiros. Revista de Administração UFSM, Santa Maria, v. 6, n. 1, p. 119-138, jan./mar. 2013
MINISTÉRIO DA JUSTIÇA. Sistema Nacional de Defesa do Consumidor. Sistema Nacional - SNDC, 2012. Disponível em: http://portal. mj.gov.br. Acesso em: 06.02.2013.

MULLINEUX, A. The public duties and social responsibilities of big british banks. International. Advances In Economic Research, v. 17, n.4, p. 436-450, 2011.

OECD. ORGANISATION FOR ECONOMIC CO-OPERATION AND DEVELOPMENT. G20 high-level principles on financial consumer protection. Paris, 2011. Disponível em: http:// www.oecd. org/dataoecd/58/26/ 48892010. pdf. Acesso em: 30.11.2012.

ORO, I. M.; RENNER, S.; BRAUN, M. Informações de Natureza Socioambiental: Análise dos Balanços Sociais das Empresas Integrantes do Índice de Sustentabilidade Empresarial da BM\&FBOVESPA. Revista de Administração UFSM, Santa Maria, v. 6, Edição Especial, p. 247-262, maio. 2013.

PESTANA, M.H.; GAGEIRO, J. N. Análise de dados para ciências sociais. A complementaridade do SPSS. 4 ed. Lisboa: Sílabo, 2005.

RYNGELBLUM, A. L.; VIANNA, N. W. H.; RIMOLI, C.A. The ways companies really

answer consumer complaints. Marketing Intelligence \& Planning, v. 31, n. 1, p. 54-71,

2013.

SAMPIERI, R. H.; COLLADO, C. F.; LUCIO, P. B. Metodologia de Pesquisa. 3. ed. São Paulo: Mc Graw-Hill, 2006, 584 p.

SIEGEL, S.; CASTELLAN Jr., N. J. Estatística nãoparamétrica para ciências do comportamento. 2. ed. Porto Alegre: Artmed, 2006.

SINGH, J. A typology of consumer dissatisfaction response styles. Journal of Retailing, n.1, p. 57-90, 1990.

SINGH, J. Consumer complaint intentions and behavior: definitional and taxonomical issues. 
Journal of Marketing, v. 52, n. 1, p.93-107, 1988.

TEIXEIRA, M. G. C.; MORAES, I. B. O diálogo com stakeholders na teoria e na prática: análise da relação de uma empresa pública do setor industrial com seus stakeholders, para a construção de uma política de responsabilidade social. Revista de Administração UFSM, Santa Maria, v. 6, Edição Especial, p. 211-228, maio. 2013.

TENENHAUS, M.; YOUNG, F. W. An analysis and synthesis of multiple correspondence analysis, optimal scaling, dual scaling, homogeneity analysis and other methods for quantifying categorical multivariate data. Psychometrika, v. 50, n.1, p. 91-119, 1985.

YEUNG, S. The role of banks in corporate social responsibility. Journal of Applied Economics and Business Research. v. 1, n. 2, p.103-115, 2011. 